\title{
AN INVESTIGATION INTO CERTAIN ASPECTS OF PERTUSSIS
}

\author{
BY \\ C. W. KESSON and MARIANNE HARLING \\ From The Children's Department, St. George's Hospital, London, and Division 1 London County Council
}

(RECEIVED FOR PLBLICATION APRIL 29, 1953)

The primary object of the present study, which was carried out at the Victoria Hospital for Children, Chelsea, was to investigate the incidence and course of the pulmonary complications which persist for more than two months after the onset of pertussis, and to determine whether these effects of whooping cough on the lung could be avoided. Pertussis is most dangerous in early life and we restricted our enquiry to children under the age of 4 years. An attempt was made to see each child approximately three months after the onset of the illness, for we considered that those patients who were likely to develop bronchiectasis would be found amongst those whose radiographs still showed pulmonary collapse at this stage.

During the course of the investigation we were able to study the probable source of infection in our patients and also the spread of the disease to susceptible children in their household.

\section{Procedure}

Our patients were those who had been notified as suffering from this infection in Chelsea, Fulham and South Kensington during the period January 1 to December 31, 1951.

A letter giving a brief explanation of the project was sent to the medical practitioner who had notified the case. If he agreed to the child attending the hospital for a medical examination he was asked to forward a card to the parents which gave an appointment for the visit. Some of the patients were referred by practitioners as cases of suspected pulmonary collapse before our request was received.

At the first interview the history was recorded and the child examined. A chest radiograph in the antero-posterior plane was taken and a tuberculin jelly test with control was applied to the back. The mother was asked to come again with her child a week later, and if the radiograph showed any abnormality further films were then taken. The medical practitioner was notified of the results of the examination, and patients requiring further attention were observed until recovery was complete.

\section{Results}

During the year 1951, 357 children under 4 were notified as suffering from pertussis in the area in which the present investigation was conducted. We know of five fatalities. The study refers to 224 children who attended our clinic.

In the cases under review $38\left(17^{\circ}{ }_{\mathrm{o}}\right)$ had received a complete course of prophylactic inoculations against pertussis, $171(76 \cdot 3 \%)$ were given none at all, and in $15(6.7 \%)$ the evidence was inadequate for any definite conclusions to be reached.

The patients could be divided into four groups: (A) Those who were symptom-free and who showed no clinical or radiological abnormality. (B) Those who had a cough but who showed no clinical or radiological abnormality. (C) Those with a cough and clinical evidence of infection in the upper respiratory passages but who showed no clinical or radiological evidence of pulmonary disease. (D) Those with clinical and/or radiological evidence of pulmonary disease.

Table 1 shows that $21 \cdot 4^{\circ}$ of the children were symptom free when first examined, $37 \cdot 1 \%$ had a residual cough as the only abnormality, while a further $29.0 \%$ who still suffered from a cough were found to have an upper respiratory tract infection which was considered adequate in each case to

TABLE 1

RESULTS AT INITIAL EXAMINATION

\begin{tabular}{|c|c|c|c|c|c|c|}
\hline \multirow{2}{*}{\multicolumn{2}{|c|}{$\begin{array}{l}\text { Clinical } \\
\text { Group }\end{array}$}} & \multicolumn{4}{|c|}{$\begin{array}{l}\text { Time of Initial Examination after } \\
\text { Onset of Pertussis in Months }\end{array}$} & \multirow[t]{2}{*}{ Total } \\
\hline & & $2-3$ & -4 & -5 & -6 & \\
\hline $\begin{array}{l}\mathbf{A} \\
\mathbf{B} \\
\mathbf{C} \\
\mathbf{D}\end{array}$ & $\begin{array}{l}\cdots \\
\cdots \\
\cdots\end{array}$ & $\begin{array}{l}17 \\
37 \\
28 \\
12\end{array}$ & $\begin{array}{l}17 \\
29 \\
19 \\
11\end{array}$ & $\begin{array}{r}5 \\
12 \\
9 \\
3\end{array}$ & $\begin{array}{l}9 \\
5 \\
9 \\
2\end{array}$ & $\begin{array}{l}48\left(21 \cdot 4{ }^{\circ}\right) \\
83\left(37 \cdot 10^{\circ}\right) \\
65(29 \cdot 0 \%) \\
28(12 \cdot 5 \%)\end{array}$ \\
\hline Total & $\cdots$ & $\begin{array}{c}94 \\
(42 \%\end{array}$ & $(36.9 \%)$ & $\left(12 \cdot 90_{0}\right)$ & $\left(11 \cdot 20^{\circ}\right)$ & 224 \\
\hline
\end{tabular}


explain this symptom. Furthermore these children showed no clinical or radiological evidence of lung involvement. Finally 28 patients $(12 \cdot 5 \%)$ showed radiological evidence of pulmonary disease. In each case this was considered to be collapse of the lung due to viscid secretion blocking the bronchial lumen. Thirty-six lobes of the lungs were affected. The anatomical distribution is shown in Table 2 .

TABLE 2

ANATOMICAL DISTRIBUTION OF LUNG COLLAPSE

\begin{tabular}{lllll}
\multicolumn{1}{c}{ Lobe } & & & \multicolumn{2}{c}{ Number of Cases } \\
\hline Right upper lobe & $\ldots$ & $\ldots$ & 2 \\
Left upper lobe $\ldots$ & $\ldots$ & $\ldots$ & 2 \\
Left lingula & $\ldots$ & $\ldots$ & $\ldots$ & 1 \\
Left lower lobe $\ldots$ & $\ldots$ & $\ldots$ & 6 \\
Right middle lobe & $\ldots$ & $\ldots$ & 6 \\
Right lower lobe & $\ldots$ & $\ldots$ & 19 \\
\hline
\end{tabular}

Only 21 out of the 28 patients showing pulmonary collapse could be studied as closely as we had hoped. Of the seven defaulters, three moved from the district and remained untraced. The remaining four were seen two years after the onset of pertussis by which time their recovery was complete both clinically and radiologically. An analysis of the 21 cases shows that in 13 re-aeration occurred within one month of the detection of the collapse, in a further six within two months, whereas in the other three expansion was complete in four, seven and 14 months respectively.

In our series pulmonary collapse was usually of minor degree and short duration. In only two children was admission to hospital considered necessary and both of these had superimposed lung infection. No case was recognized by us as progressing to bronchiectasis.

\section{Tuberculin Skin Sensitivity}

At the first visit a tuberculin jelly with control was applied to the skin of the scapular region of every patient. The mother was instructed to remove the plaster after an interval of $\mathbf{4 8}$ hours and to examine the skin the following day and daily until she came back to the hospital the following week. She was asked to record any changes she had noted. The test was finally read at the second visit, on the seventh day. Of the 193 patients who complied with this procedure, 192 gave a negative reaction to the tuberculin jelly. The only positive result was given by a child who had been previously vaccinated with B.C.G.

\section{Source of Infection}

Table 3 shows the probable source of infection in the 224 cases. This was considered to be known in over $60 \%$ of the cases. An older child in the house was most often responsible. Wherever the primary case was known the mother was asked whether she thought that a spread to susceptible children could have been prevented. From the answers received we reached the conclusion that the difficulty of early diagnosis in pertussis would render ineffective the isolation of cases occurring at home, even if this were a practical proposition. It seems certain that the only way to eradicate pertussis would be a safe. efficient, prophylactic inoculation.

\section{Spread of Infection in the Home}

In assessing the incidence of infection in children in contact with pertussis in their own homes (Table 4)

TABLE 4

SPREAD OF INFECTION IN THE HOME

\begin{tabular}{|c|c|c|c|c|}
\hline \multirow{2}{*}{ Age } & \multicolumn{2}{|c|}{ Susceptible } & \multirow{2}{*}{$\begin{array}{l}\text { Immune } \\
\text { (Natural } \\
\text { Infection) }\end{array}$} & \multirow[t]{2}{*}{ Unknown } \\
\hline & Affected & Not affected & & \\
\hline \multirow[t]{2}{*}{$\begin{array}{l}0-1 \\
-2 \\
-3 \\
-4\end{array}$} & $\begin{array}{l}12 \\
23 \\
30 \\
23\end{array}$ & $\begin{array}{r}4 \\
4 \\
5 \\
11\end{array}$ & $\begin{array}{l}6 \\
3 \\
6 \\
9\end{array}$ & $\begin{array}{r}4 \\
4 \\
10 \\
1\end{array}$ \\
\hline & 88 & $\overline{24}$ & 24 & $\overline{19}$ \\
\hline
\end{tabular}

only those under the age of 12 years were considered.

Of the 112 susceptible children, $78.6 \%$ were affected. This figure is comparable to that given in the Medical Research Council Report (1951) where it was found that the average attack rate in home exposures among non-vaccinated children was $87 \cdot 3 \%$. In only one trial was an attack rate of under $75 \%$ of cases reported.

TABLE 3

SOURCE OF INFECTION

\begin{tabular}{|c|c|c|c|c|c|c|}
\hline $\begin{array}{l}\text { Age of Cases } \\
\text { in Years }\end{array}$ & $\begin{array}{l}\text { Sibling or Relative } \\
\text { in the Household }\end{array}$ & Playmate & Hospital & Nursery & Total Known & Total Unknown \\
\hline \multirow[t]{2}{*}{$\begin{array}{l}0-1 \\
-2 \\
-3 \\
-4\end{array}$} & $\begin{array}{l}25 \\
30 \\
21 \\
10\end{array}$ & $\begin{array}{r}6 \\
6 \\
11 \\
10\end{array}$ & $\begin{array}{l}1 \\
4 \\
9 \\
5\end{array}$ & $\begin{array}{l}2 \\
1 \\
2 \\
0\end{array}$ & $\begin{array}{l}34 \\
41 \\
43 \\
25\end{array}$ & $\begin{array}{l}17 \\
24 \\
16 \\
24\end{array}$ \\
\hline & $\overline{86}\left(38 \cdot 4_{0}^{\circ}\right)$ & $\overline{33}\left(14 \cdot 7^{\circ}\right)$ & $\overline{19}(8 \cdot 5 \%)$ & $\overline{5}(2 \cdot 2 \%)$ & $\overline{443}(63 \cdot 8 \%)$ & $\overline{81}\left(36 \cdot 2{ }_{0}^{\circ}\right)$ \\
\hline
\end{tabular}




\section{Discussion}

The sole pulmonary complication found to be present in this series was that of lung collapse. In only two out of the 28 cases showing this condition was it possible to make the diagnosis on the physical signs. We found that a patient showing clinical evidence of generalized bronchitis would, on radiological examination, prove to have pulmonary collapse. Only a routine chest radiograph would detect the maximum number of cases of lung collapse since two of the patients with radiological evidence of collapse were without symptoms or abnormal physical signs.

The differentiation between collapse and consolidation may prove difficult and post-mortem studies in cases of pertussis usually show that the two processes have been coexistent. To justify a diagnosis of lung collapse as opposed to consolidation certain facts were taken into consideration. Some of the radiographs of patients with pulmonary disease showed conclusively that the affected area of lung had decreased in volume. In others, where a small area of lung was involved the absence of the general manifestations of infection made one consider that the lesions were largely if not entirely due to collapse. Finally, our patients were seen more than two months after the onset of pertussis, and their maintenance of good general health in the intervening period suggested that infection had not played a significant role.

It is interesting to compare the lobar distribution of the lung collapse with that reported by other investigators. Kohn, Schwartz, Greenbaum and Daly (1944) surveyed 222 cases of pertussis and commented on the frequency with which the right middle lobe was involved. Nicholson (1949) in his study of 44 patients found the right lower lobe to be affected 35 times, the left lower lobe 19 times and the right middle lobe 10 times. Lees (1950) reviewing 150 cases of pertussis found the left lower lobe was involved on 43 occasions, the right lower lobe on 31 and the right middle lobe on eight. These studies were all made on children who had been admitted to hospitals and are therefore not strictly comparable with the present series.

Laennec (1834) first drew attention to the fact that bronchiectasis may follow an attack of pertussis. It is at present held that pulmonary collapse is an important and perhaps an essential feature in the pathogenesis of permanent bronchial dilatation. Correlating these views, the early detection of pulmonary collapse complicating pertussis, and re-aeration of the lung should cause a reduction in the number of cases of bronchiectasis.

Lees (1950) found the highest incidence of lung de-aeration occurred at the fourth week of the illness and in only a few cases did it persist longer than five weeks. Our results confirm that the pulmonary collapse occurring in pertussis is usually of short duration and spontaneous re-aeration follows within a few weeks. Nevertheless we consider it essential that this complication of whooping cough be recognized, for if the area involved is extensive or complicated by infection, or should there be no improvement within two or three weeks of its demonstration, in-patient treatment is advisable to hasten the expansion of the lung.

In his study of 150 cases of pertussis Lees (1950) carried out bronchography in 49 patients but in none did he observe permanent bronchial dilatation. In our series no case was recognized as progressing to bronchiectasis, nor did we consider there to be any indication for bronchography. The results suggest that the incidence of bronchiectasis following pertussis is not as high as is frequently suggested.

In conclusion, the small number of tuberculin reactors in our series is partly explained by the age of the children concerned, but is in accord with the results we are obtaining at a welfare centre in Kensington. The figures do not support the belief that pertussis favours the development of tuberculosis.

A review of 224 cases of pertussis showed that lung complications occurred in $28(12.5 \%)$. The sole complication detected was pulmonary collapse.

In most children with pulmonary collapse following this infection lung re-expansion was spontaneous and complete, usually within two months.

A chest radiograph should be taken in all young children about two to three months after pertussis.

Prevention of contact with a sufferer is not often a practical proposition and will not cause any appreciable decrease in the number of those infected, nor raise the age incidence of the disease. Safe and efficient vaccination seems to be the only solution.

The incidence of pertussis in children exposed to the infection in their own homes was $76.3 \%$.

Pertussis does not appear to favour the development of tuberculosis.

This investigation was made possible by the cooperation of many local practitioners, Dr. Violet Russell and her Staff at Division 1, and the Medical Officer of Health and members of L.C.C. Research Committee.

REFERENCES

Kohn, J. L., Schwartz, I., Greenbaum, J. and Daly, M. M. I. (1944). Amer. J. Dis. Child., 67, 463.

Laennec, R. T. H. (1834). A Treatise on the Diseases of the Chest and on Mediate Auscultation, 4th ed. Translated by John Forbes, London. (1st French ed. 1819: 1st English ed. 1821.)

Lees, A. W. (1950). Brit. med. J., 2. 1138.

Medical Research Council Report (1951). Ibid., 1, 1463.

Nicholson, D. P. (1949). Archives of Disease in Childhood, 24, 29. 